\title{
Characterization of size, shape and pattern of flow in the neo-aorta and pulmonary artery in a patient following an innovative technique of repair for truncus arteriosus
}

${ }^{1}$ Biomedical Engineering and Innovation Laboratory, Aswan Heart Centre, Magdi Yacoub Heart Foundation, Egypt

${ }^{2}$ Department of Surgery, Aswan Heart Centre, Magdi Yacoub Heart Foundation, Egypt

3 Department of Radiology, Aswan Heart Centre, Magdi Yacoub Heart Foundation, Egypt

${ }^{4}$ National Heart and Lung Institute, Imperial College London, UK

*Email:m.yacoub@imperial.ac.uk https://doi.org/

$10.21542 /$ gcsp. 2019.18

Received: 16 August 2019 Accepted: 28 August 2019 (C) 2019 The Author(s), licensee Magdi Yacoub Institute. This is an open access article distributed under the terms of the Creative Commons Attribution license CC BY-4.0, which permits unrestricted use, distribution and reproduction in any medium, provided the original work is properly cited.
Amr El Sawy ${ }^{1}$, Mohamed Nagy ${ }^{1}$, Ahmed Afifi ${ }^{2}$, Hatem Hosny², Soha Romeih ${ }^{3}$, Heba Aguib ${ }^{1}$, Magdi Yacoub ${ }^{2,4 *}$

\section{ABSTRACT}

Background. Truncus arteriosus (TA) caries a very poor prognosis. In the absence of early correction, only 12 percent of patients born with this anomaly survive beyond one year. There is no agreement about the best method of surgical correction of this anomaly. We have devised an innovative valveless technique using autologous arterial tissue to repair TA.

Objectives. Characterizing the size, shape and pattern of flow in the neo-aorta and pulmonary artery, in a patient following the new technique.

Patient and Methods. Cardiac MRI and multislice CT imaging, followed by offline computerized image analysis was used in a patient aged 3 months, within 3 weeks of operating.

Results. The size, shape and topology of the neo-aorta and pulmonary artery, approximated that present in normal hearts. The pattern of flow in the reconstructed vessels was laminar, throughout the cardiac cycle with minor acceleration during systole. The pulmonary regurgitation resulting from the absence of a valve occurred during late diastole, and was well tolerated. The size of the right ventricle diminished considerably following operation, and the right ventricular ejection fraction was supernormal.

Conclusion. This early study in one patient provides new unique data of the size, shape, topology and pattern of flow in the neo-aorta and pulmonary artery, which appear to approximate normality. The long-term results of this promising operation need to be studied.
Cite this article as: El Sawy A, Nagy M, Afifi A, Hosny H, Romeih S, Aguib H, Yacoub M.

Characterization of size, shape and pattern of flow in the neo-aorta and pulmonary artery in a patient following an innovative technique of repair for truncus arteriosus, Global Cardiology Science and Practice 2019:18 https://doi.org/10.21542/gcsp.2019.18 


\section{INTRODUCTION}

Truncus arteriosus carries an extremely poor prognosis if not corrected in infancy, with only $12 \%$ survival beyond one year ${ }^{4}$. Unfortunately, to date, there is no agreement about the best method of repairing this anomaly. Currently used techniques consist of separating the pulmonary artery from the truncus, followed by joining the pulmonary arteries to the right ventricle after closing the ventricular septal defect (VSD). To bridge the gap between the pulmonary arteries and the right ventricle, a variety of conduits and patches are used ${ }^{1-3,5,6,8,9}$. These techniques can result in severe hemodynamic disturbances both in the short and long term ${ }^{7}$ and require relatively frequent replacement, with its associated morbidity and mortality to consider.

To circumvent some, or all, of these problems we have developed and used an innovative technique utilizing autologous vascular tissue. This technique is designed to refashion the truncus arteriosus into neo-aorta and neo-pulmonary arteries with attempts of normalizing the pattern of flow to the aortic arch and pulmonary artery branches. In addition, it recreates a sinotubular junction which could improve truncal valve regurgitation. We describe, for the first time, the early effects of this technique on the size, shape and pattern of flow in the neo-aorta and pulmonary artery.

\section{PATIENT AND METHODS}

A three-month-old female patient $\left(B S A=0.3 \mathrm{~m}^{2}\right)$ was diagnosed as truncus arteriosus type I, with an arterial oxygen saturation of $87 \%$ and a thickened truncal valve with maximum pressure gradient across $30 \mathrm{mmHg}$ and moderate regurgitation. The pulmonary artery branches were of good size. Biventricular function was normal despite marked left and right ventricular hypertrophy and dilatation. The follow up imaging was done within the first three weeks after the operation.

\section{The new technique, in short}

The new technique consists of transecting the truncus above and below the origin of the pulmonary artery (PA), followed by anastomosis of the ascending aorta to the root of the truncus. The mobilized segment of the truncus carrying the origin of the PA is used to refashion a new RV outflow which is anastomosed to a window on the anterior surface of the RV. The outlet VSD is closed through the same window to refashion a new LV outflow joining the LV to the neo-aorta.

\section{Image acquisition and $3 \mathrm{D}$ reconstruction}

Imaging was performed using a 128 dual source multi-slice detector CT scanner (Siemens Somatom Definition Flash, Erlangen, Germany) using retrospective ECG triggering. Bolus tracking was done in the proximal trunk. Imaging parameters used for scanning include: detector collimation of $128 \times 0.6 \mathrm{~mm}$, pitch of 0.2 , gantry rotation time of $280 \mathrm{~ms}$, tube voltage of $80-120 \mathrm{kV}$ and fully automated real-time anatomy-based dose regulation (CARE Dose 4D) to reduce radiation exposure.

The size and shape of the vessels and the topology was analyzed using Mimics Research version 21 and 3-matic (Materialise, Leuven, Belgium).

CMR was performed with 1.5 T scanner (Siemens Sonata, Erlangen, Germany) using retrospective ECG triggering. SSFP end- expiratory breath-hold cines were acquired for LVOT and RVOT view on 2 orthogonal planes, with slice thickness of eight $\mathrm{mm}$. The temporal resolution was $21 \pm 1 \mathrm{~ms}$.

Pattern of flow was characterized by CMR using a 4D flow acquisition sequence and Medis ${ }^{\circledR}$ research program for $4 \mathrm{D}$ Flow post-processing. Velocity was encoded in three 
(a)

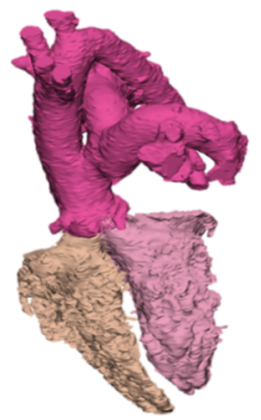

(b)

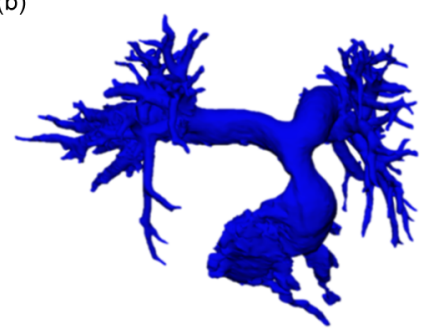

(c)

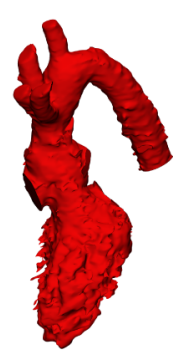

Figure 1. 3D anatomical model showing topology of both ventricles and corresponding great arteries. Pre-operative image: position of the truncus in relation to the right and left ventricles (a), Postoperative neo-pulmonary and right ventricle (b), Post-operative neo-aorta and left ventricle (c).

orthogonal directions, and the images were acquired during free breathing by an imaging sequence with retrospective electrocardiogram gating (10\% acceptance window, 30 reconstructed cardiac phases).

A computational fluid dynamic simulation (CFD) of the neo-pulmonary artery, along with its two bifurcations (right pulmonary artery and left pulmonary artery) was performed. The boundary conditions for the inlet and the two outlets were obtained from the phase-contrast magnetic resonance imaging (PC-MRI), from which the flow velocity data was extracted.

\section{RESULTS}

\section{Pre- and post-operative topology}

This showed the position of the truncus arteriosus located on top of both the right and left ventricles and overriding the outlet VSD. The origin of the pulmonary artery was located on the left lateral aspect of the truncus immediately above the root (Figure 1a). The main pulmonary artery is directed upwards and to the left before bifurcating.

Following operation, the mobilized main pulmonary artery arises from a tailored outflow at the front of the right ventricle and is directed upwards and to the right similar to the location of a normal pulmonary artery. The preserved pulmonary artery bifurcation results in a near normal angle between the branches (Figure $1 b$ ).

Figure $1 \mathrm{c}$ shows the origin of the neo-aorta from the left ventricle with a short outflow tract created by the VSD patch. The ascending aorta is markedly shortened with creation of a sinotubular junction.

The interrelation between the two ventricles and great arteries shows normal direction and crossing of the neo-aorta and pulmonary artery (Figure 2).

\section{Shape and size of the arteries}

Preoperatively, the truncus consisted of a bulbous root with absence of a sinotubular junction. A short main pulmonary artery arose from the common trunk $2 \mathrm{~mm}$ above the top of the intercoronary commissure producing marked distortion in the shape of the truncal outflow. The ascending aorta immediately distal to the pulmonary ostium is elongated (measurements, Figure 3).

Post-operatively the neo-aorta has accentuated sinotubular junction with a markedly shortened ascending aorta (Figure 4). The neo-pulmonary artery configuration and measurements are reduced to near-normal (Figure 5). 


$$
\frac{n}{n}
$$




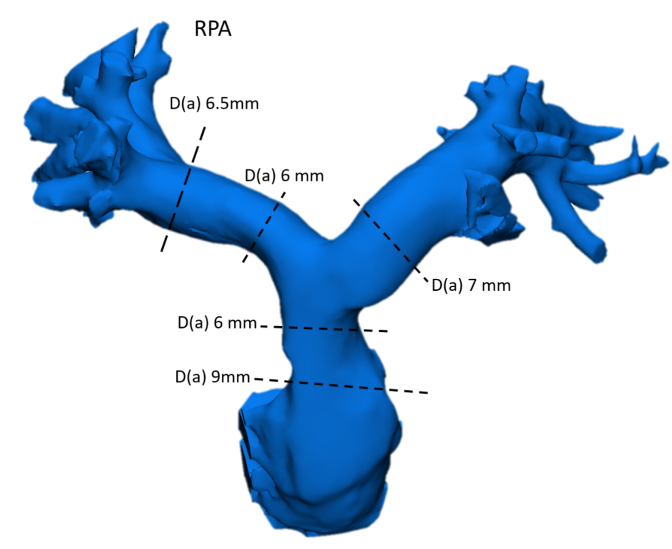

Figure 5. Shape and measurements of the neo-pulmonary artery, $D(a)$ is diameter based on area measurement.
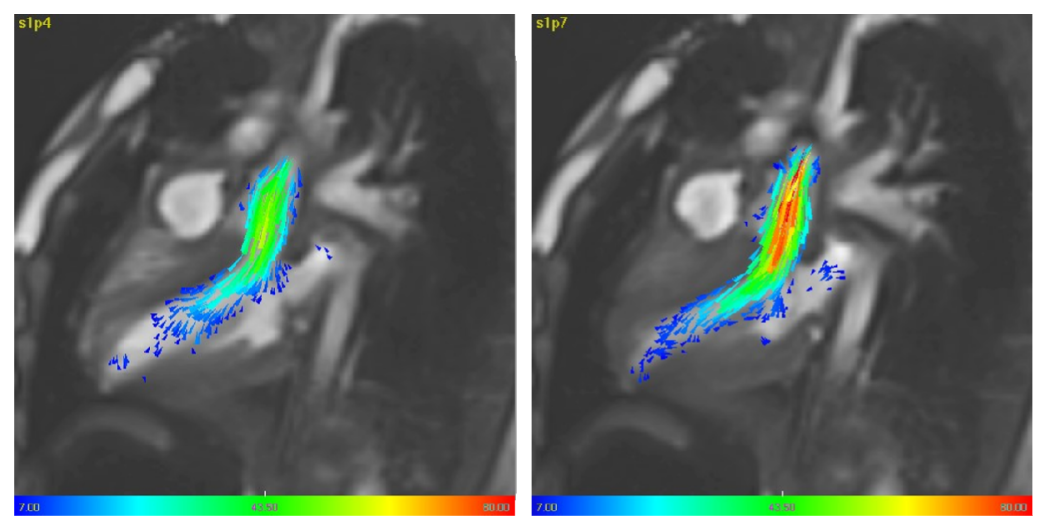

Figure 6. 4D Pattern of flow of the neo-aorta at: early systole (left) and peak systole (right).

\section{POST-OPERATIVE PATTERN OF FLOW IN THE ARTERIES (4D)}

\section{Neo-aorta}

This showed laminar flow in early systole with slight acceleration during peak systole without evidence of disturbed flow (Figure 6).

\section{Neo-pulmonary artery}

The flow from the right ventricle through the very short tailored outflow to the normal pulmonary artery bifurcation showed slight acceleration of flow only at peak systole (Figure 7). During diastole there was a reversal of flow only during the late diastolic phase. This did not interfere with normal pattern of filling of the inflow of the right ventricle (Figure 7).

The flow profile in the neo-aorta and pulmonary artery during systole shows fast flow in the neo-aorta, approximating normal aortic flow. In the pulmonary artery the flow showed slower rise and fall with reversal of flow during late diastole which amounted to approximately $1 / 3$ of the cardiac output (Figure 8). This, however did not result in any residual volume in the right ventricle with a very small end-systolic volume (Figure 1 b). 

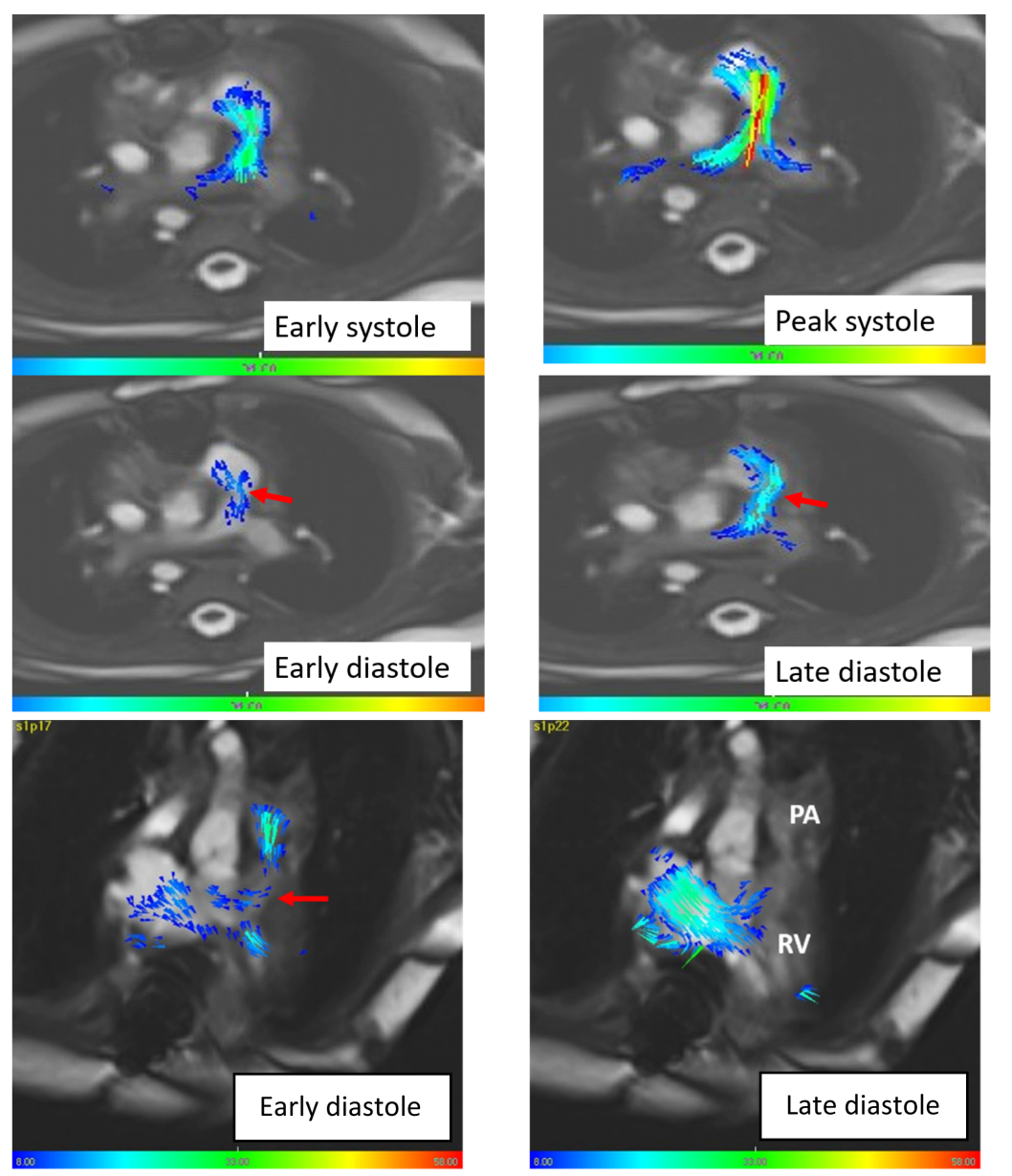

Figure 7. 4D Pattern of flow of the neo-pulmonary at: early systole, peak systole, early diastole and late diastole.

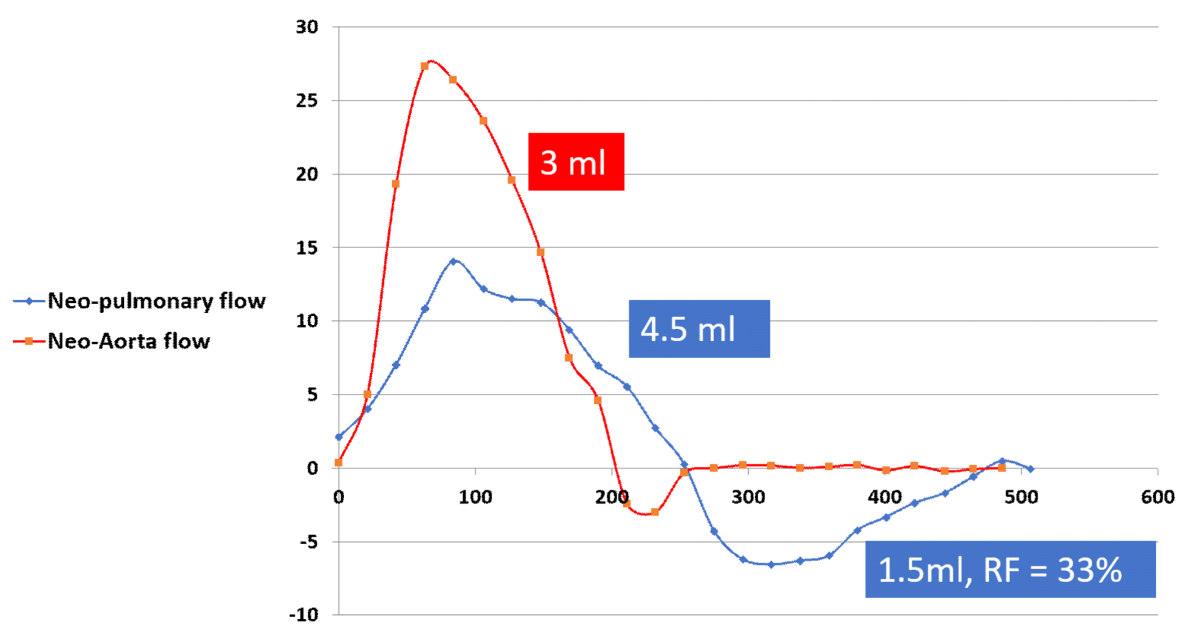

Figure 8. Flow profile of the neo-aorta and neo-pulmonary arteries.

\section{Neo-pulmonary artery bifurcation}

This was quantified by computational fluid dynamics (CFD) which showed smooth streamlines from the main pulmonary artery to both branches during systole and diastole (Figure 9). 

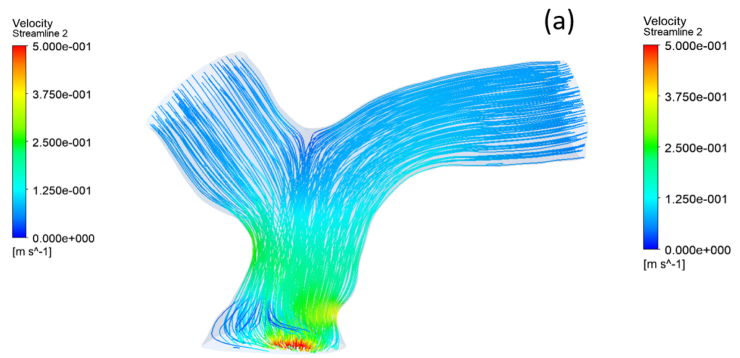

(b)
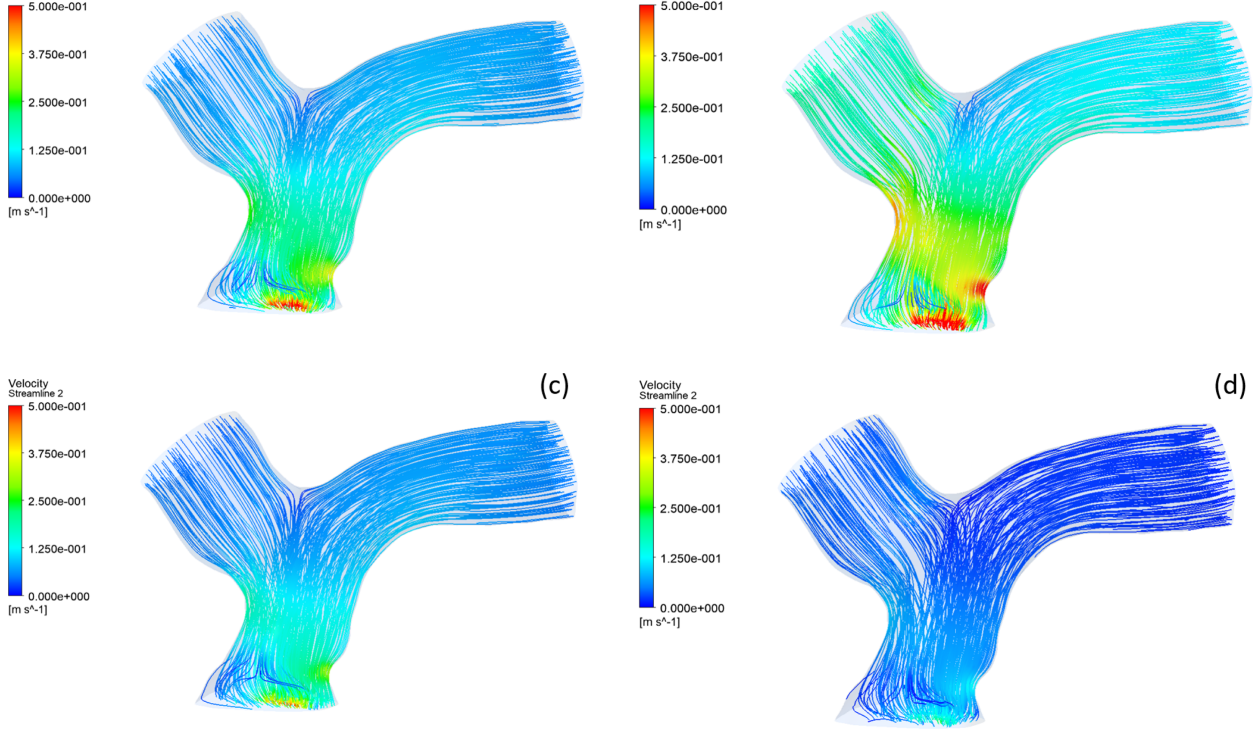

(d)

Figure 9. Velocity streamlines produced by CFD simulation for the neo-pulmonary artery at: early systole (a), mid-systole (b), late systole (c), and mid-diastole (d).

\section{Conclusion}

This study has shown, for the first time, the specific structural features and pattern of flow within the neo-aortic and pulmonary vessels following an innovative repair of truncus arteriosus in a patient shortly after operation. These short-term results are extremely promising and await confirmation in a larger number of patients followed up for longer periods of time.

\section{ACKNOWLEDGEMENTS}

The authors would like to thank Siemens Healthineers (Erlangen, Germany) for providing software and technical support for research purposes in Aswan Heart Centre and also to acknowledge Abdel Rahman Sultan, Hussam El Nashar and Malak Sabry for performing the CFD study from the Biomedical Engineering and Innovation Laboratory in Aswan Heart Centre.

\section{REFERENCES}

[1] McGoon DC, Rastelli GC, Ongley PA. An operation for the correction of Truncus Arteriosus. JAMA. 1968;205(2):69-73. doi: 10.1001/jama.1968.03140280023007.

[2] Reid KG, Godman MJ, Burns JE. Truncus arteriosus: Successful surgical correction without the use of a valved conduit. British Heart Journal. 1986;56(4):388-390.

[3] Barbero-Marcial ML, Riso AD, Atik E, Jatene AD. A technique for correction of truncus arteriosus types I and II without extracardiac conduits. The Journal of thoracic and cardiovascular surgery. 1990;99(2):364-9.

[4] Kirklin JW, Barratt-Boyes BG. Truncus arteriosus. In: Kirklin JW, Barratt-Boyes BG, eds. Cardiac surgery. 2nd edition. New York: Churchill livingstone; 1992:1131-52.

[5] Lacour-Gayet F, Serraf A, Komiya T, Sousa-Uva M, Bruniaux J, Touchot A, Planche C. Truncus arteriosus repair: Influence of techniques of right ventricular outflow tract reconstruction. Journal of Thoracic and Cardiovascular Surgery. 1996;111(4):849-856. doi: 10.1016/So022-5223(96)70346-X.

[6] Thompson LD, McElhinney DB, Reddy VM, Petrossian E, Silverman NH, Hanley FL. Neonatal repair of truncus arteriosus: Continuing improvement in outcomes. Annals of Thoracic Surgery. 2001;72(2):391-395. doi: 10.1016/So003-4975(01)02796-5.

[7] Niemantsverdriet MBA, Ottenkamp J, Gauvreau K. Determinants of right ventricular outflow tract conduit longevity: a multinational analysis. Congenital Heart Disease. 2008;3(3):176-184. doi: 10.1111/j.17470803.2008.00190.x. 
[8] Alfieris GM, Gangemi JJ, Schiralli MP, Swartz MF, Cholette JM. Modified repair of truncus arteriosus to maintain pulmonary artery architecture. Annals of Thoracic Surgery. 2010;90(3):1038-1039. doi: 10.1016/j.athoracsur.2009.11.045.

[9] Salem AS. Early outcome of window like repair and valveles RV to PA connection for type one truncus arteriosus. The Egyptian Heart Journal. 2014;66(1):9. doi: 10.1016/j.ehj.2013.12.026. 